бюджетное учреждение науки Институт аграрных проблем Российской академии наук. Россия.

Трифонова Елена Николаевна, канд. экон. наук, доиент, старший научный сотрудник лаборатории инновациионнгго развития производственного потенциала агропромышленного комплекса, Федеральное государственное бюджетное учреждение науки Институт аграрных проблем Российской академии наук. Россия.
410012, г. Саратов, ул. Московская, 94. Тел.: (8452) 26-35-89

ключевые слова: производственный потенизиал; кластерный анализ; молочный подкомплекс; самообеспеченность; импортозамещение; эффективность производства.

\title{
THE FACTORS OF INCREASING THE EFFICIENCY OF THE PRODUCTION POTENTIAL OF DAIRY CATTLE AND MILK INDUSTRY OF RUSSIA
}

Andryshenko Sergey Anatolyevich, Doctor of Economic Sciences, Professor, Head of the laboratory of Innovative Development of Production Potential of Agro-industrial Complex, Federal State Budgetary Institution of Science Institute of Agrarian Problems of Russian Academy of Science. Russia.

Vasylchenko Marianna Yakovlevna, Candidate of Economic Sciences, Associate Professor, Senior Researcher of the laboratory of Innovative Development of Production Potential of Agro-industrial Complex, Federal State Budgetary Institution of Science Institute of Agrarian Problems of Russian Academy of Science. Russia.

Trifonova Elena Nokolaevna, Candidate of Economic Sciences, Associate Professor, Senior Researcher of the laboratory of Innovative Development of Production Potential of Agro-industrial Complex, Federal State Budgetary Institution of Science Institute of Agrarian Problems of Russian Academy of Science. Russia.

Keywords: production potential; cluster analysis; milk subcomplex; self-sufficiency; import substitution; production efficiency.
The development of the production potential of dairy cattle breeding and processing industry should be aimed at meeting the challenges of both ensuring food security and increasing the share of the gross domestic product produced in the agro-industrial complex. Indicators that determine the marginality of both agriculture and the dairy industry are used in this study as indicators of the efficiency of the dairy sub-sector. Factors of increasing the efficiency of the production potential of a single reproductive chain of the Russian dairy product complex, taking into account regional specificities, are identified and analyzed, and reserves for their growth are justified. The use of cluster analysis in the study of the potential for the development of meat and dairy cattle breeding has made it possible to determine regional differences in the level of intensity of milk and meat production, and to identify regional factors for increasing the efficiency of dairy cattle and processing industries that contribute to the creation of high marginal value added.

\section{СОВРЕМЕННОЕ СОСТОЯНИЕ И ТЕНДЕНЦИИ РАЗВИТИЯ ПРОИЗВОДСТВА И РЕАЛИЗАЦИИ ОВОЩЕЙ ЗАЩИЩЕННОГО ГРУНТА В УСЛОВИЯХ ИМПОРТОЗАМЕЩЕНИЯ}

\author{
БРЕДНЕВ Владислав Дмитриевич, Саратовский государственный аграрный университет \\ имени Н.И. Вавилова
}

Исследовано современное состояние развития отрасли овощеводства защищенного грунта, разобраны положительные и негативные тендениии, выявлены ключевые проблемы управления предприятиями в отрасли овощеводства защищенного грунта на современном этапе в условиях импортозамещения, сформулированы актуальные особенности развития производства и реализации овощей тепличных хозяйств, рассмотрены перспективы развития предприятий отрасли овощеводства защищенного грунта.

Введение. В последние годы политика импортозамещения в сфере АПК значительно ускорила темпы развития российских тепличных хозяйств, однако отечественных овощей на рынке всё равно не хватает. Несмотря на то, что теплицы привлекают всё новых инвесторов, в том числе тех, кто раньше не был связан с сельским хозяйством, более динамичному росту овощеводства закрытого грунта по-прежнему мешает немало барьеров, в том числе высокая стоимость энергоресурсов, сложности с финансированием проектов и зависимость от зарубежных технологий [6].

Производство тепличных овощей в РФ продолжает расти. В стране активно возводятся новые и модернизируются старые производственные мощности, внедряются современные технологии выращивания овощей в защищенном грунте. При этом большинство инвестпроектов в области тепличного овощеводства, которые планируется запустить до 2020 г., сконцентрированы преимущественно в Центральной России 
(порядка 600 га теплиц) и на Юге (более 200 га). К началу 2017 г. общая площадь теплиц в стране достигала примерно 2,3 тыс. га. Из них 600 га построены за последние пять лет, в том числе 300 га - со светокультурой.

Однако параллельно с вводом новых комплексов выводятся из эксплуатации старые. За последние пять лет построено 600 га современных теплиц, но примерно 350 га выбыло. Поэтому реальный прирост площадей зимних теплиц гораздо меньше [3].

Всего, по данным Росстата, производство отечественных овощей закрытого грунта выросло с 690 тыс. т в 2014 г. до 814 тыс. т - в 2016 г. Ожидается, что к 2020 г. производство возрастет до 1720 тыс. т/г., для чего в госпрограмме предусмотрено субсидирование затрат на строительство теплиц (3-5 млрд руб. ежегодно). В 2016 г. на рассмотрение Минсельхоза поступил 31 проект по развитию овощеводства на общую сумму около 40 млрд. руб. [4].

Согласно прогнозам, госпрограмма развития агропромышленного сектора позволит российским производителям к концу 2020 г. полностью удовлетворить потребность внутреннего рынка в огурцах и на 70-80 \% - в томатах. Кроме того, планируется включить в программу импортозамещения и выращивание грибов (сейчас около $90 \%$ рынка обеспечивает импортная продукция) [4].

Если говорить о структуре производства, то она характеризуется большим перекосом в сторону огурцов, которые занимают около 70 \% общей площади теплиц в стране. На томаты приходится 25 \%, на перцы, баклажаны, зеленные агрокультуры - 5 \%. Причина формирования такой структуры - в показателях возврата инвестиций. По информации Минсельхоза, средняя рентабельность производства огурцов в 2015 г. составила $20 \%$, а томатов - не превысила $10 \%$. Рентабельность светокультуры огурца доходила до $40 \%$, томатов - до $20 \%$ [2].

Методика исследований. В процессе работы использованы методы, применяемые в экономической науке: общенаучные (диалектический, анализа и синтеза, сравнения и аналогии, графический); специальные (системный, сравнительного анализа, статистическо-экономический).

Результаты исследований. По данным Института конъюнктуры аграрного рынка (ИКАР), доля отечественных огурцов на внутреннем рынке с 2013 г. выросла на 20 п.п. и достигла $85 \%$ (рис. 1). Такой результат был достигнут за счет увеличения объемов производства в тепличных хозяйствах (на $40 \%$ ), с одной стороны, и существенного снижения импортных поставок - с другой (на $55 \%$ ).

Доля отечественных томатов на российском рынке за рассматриваемый период выросла также на 20 п.п. - до 40 \%, причем серьезный скачек в производстве произошел именно в 2016 г. (рис. 2). Рост объемов производства томатов эксперты связывают с падением рентабель-

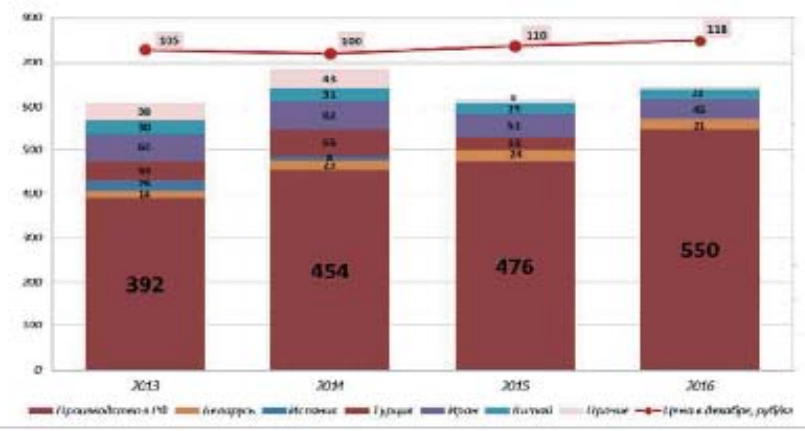

Рис. 1. Условная емкость рынка огурцов в России по годам, тыс. $m[4]$

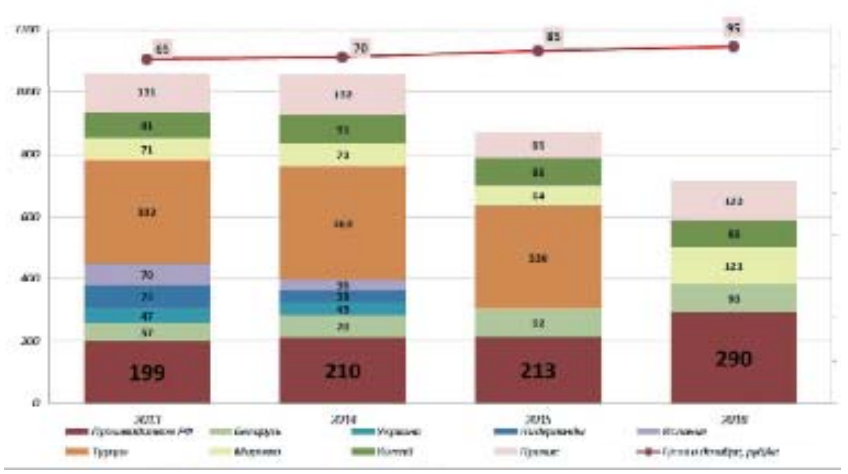

Рис. 2. Условная емкость рынка томатов в России по годам, тыс. $m[4]$

ности выращивания огурцов. Однако, если емкость рынка огурцов в натуральном выражении остается стабильной, то общая емкость рынка томатов за последние годы снизилась более чем на 30 \% (рис. 3 )

По оценке Минсельхоза России, производство тепличных овощей в 2016 г. выросло на рекордные 25-30\%. Общий сбор овощей по итогам года составит около 820-850 тыс. т [4].

Импорт свежих огурцов в РФ в 2016 г. упал примерно на четверть (рис. 4). Традиционный пик импорта пришелся на зимний период, когда мощностей отечественных теплиц не хватает чтобы полностью удовлетворить спрос на рынке. Что касается томатов, то их ввоз в страну сократился более чем на треть. Серьезный спад импортных поставок произошел в апреле-июне 2016 г., когда Турция ушла с российского рынка. Ввоз турецких томатов частично заместили Марокко и Азербайджан.

Несмотря на то, что в России активно наращивается производство огурцов и томатов, рост цен на них в зимний период сохраняется. После ухода Турции с рынка отечественные производители еще не успели нарастить выпуск. Рынок тепличных овощей быстро входит в зону высокой насыщенности и становится всё более сложным. До импортозамещения еще далеко, а получать планируемую маржу инвесторам становится нелегко уже сейчас. Однако, несмотря на очевидный прогресс в реализации программы импортозимещения, в отрасли овощеводства защищенного грунта остается ряд серьезных проблем.

Одной из ключевых проблем предприятий овощеводства защищенного грунта является мо- 


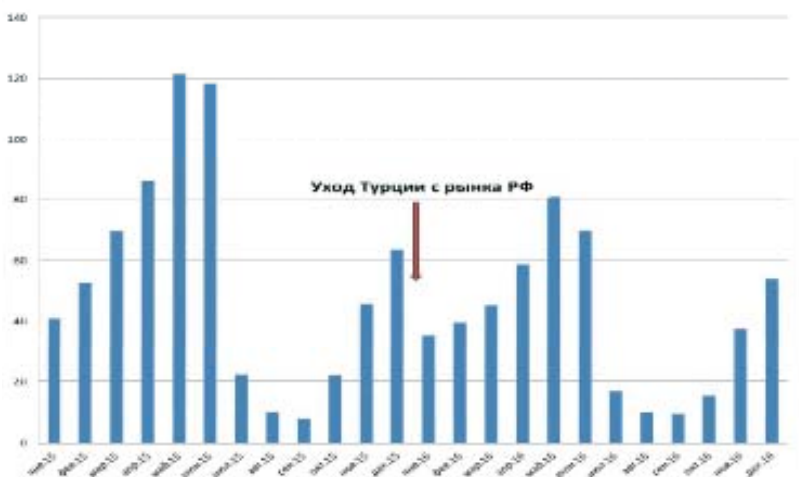

Рис. 3. Импорт свежих томатов в 2015-2016 22., mbic. $m$ [4]

ральный и физический износ основных фондов, который в настоящее время составляет $80-85$ \% (возраст большей части функционирующих теплиц 30-40 лет). Следствием физического износа теплиц является низкая урожайность тепличных культур, ограниченность ассортимента овощей, высокая энергоемкость и ресурсоемкость производства, а также высокие расходы на ремонт ограждающих конструкций и остекление, невозможность внедрения интенсивных и инновационных технологий, тяжелые условия труда. Большинство предприятий овощеводства защищенного грунта использует морально изношенные основные фонды, которые не соответствуют основным конкурентным запросам и не позволяют достигнуть требуемого уровня производительности, эргономичности и эффективности.

Следующая проблема предприятий овощеводства защищенного грунта заключается в критическом дефиците по источникам инвестиционных ресурсов. Процентная ставка по предлагаемым кредитам не позволяет окупать новые проекты даже с учетом программы субсидирования. По оценкам «Национального союза производителей овощей», эффективная ставка с учетом финансирования по длинным инвестиционным кредитам сегодня составляет $10-12 \%$, тогда как до 4 квартала 2014 г. она не превышала 5-6 \% годовых. За непродолжительное время кредитные ресурсы подорожали в два раза. По под- счетам объем инвестиций на один квадратный метр теплиц универсального формата составляет около 12-20 тыс. руб., в то время как годовая выручка без светокультуры - 3 тыс. руб./ $\mathrm{M}^{2}$, со светокультурой - до 8 тыс. руб./м². В нынешней макроэкономической ситуации окупить вложения с учетом EBITDA на уровне 45-50 \% можно за семь-восемь лет. Тепличные хозяйства тратят на оплату процентов по кредитам до 45 \% выручки, а это как раз покрывает EBITDA. Поэтому без субсидирования кредитов отрасль практически не сможет развиваться. Премьер-министр России Дмитрий Медведев в середине 2016 г. заявил о необходимости пересмотреть субсидирование кредитов аграриям так, чтобы реальная процентная ставка для них не превышала $5 \%$. Однако у кредитных организаций своя логика. Помимо растущих затрат и снижения рентабельности есть и другое ограничение - стартовая цена проекта, существенный пункт, учитывая требования банков. Любая организация всегда старается минимизировать возможные потери, особенно когда дело касается финансирования сельхозпроектов, в целом считающихся одними из самых рискованных. Банки ждут весомых гарантий со стороны бизнесменов: у заемщика требуют подтвержденный денежный поток в объеме, достаточном для исполнения обязательств перед банком без помощи субсидий. Необходимы подтвержденные собственные средства в объеме 20-30 \% от бюджета проекта, средства на уплату процентов по кредиту на инвестиционной фазе, а также залоги, полностью обеспечивающие кредит. В дополнение по проекту должна быть получена вся необходимая исходно-разрешительная документация, включая разрешение на строительство. Эта проблема, а также постоянно меняющаяся ключевая ставка ЦБ РФ не позволяют строить долгосрочные финансовые планы и начинать новые проекты. Неопределенность и нестабильность ситуации в кредитно-финансовой политике страны даже при государственной поддержке - главный барьер на пути инвестиций в отрасль. Сегодня идет активный поиск новых источников фондирования проектов в АПК, в том числе рассматривается вопрос об использовании средств негосударственных пенсионных фондов. По мнению союза, этот инструмент является наиболее осуществимым в условиях введенных против России экономических санкций. Он может значительно изменить ситуацию с финансированием в отрасли, поэтому его необходимо максимально быстро внедрить в реальную жизнь. Ресурсы пенсионных фондов во всем мире широко используются для реализации крупных инфраструктурных проектов, поэтому нужно активнее перенимать этот опыт для решения важной государственной задачи - обеспечения продовольственной безопасности страны [5].

Ограниченность инвестиционных ресурсов, связанная с эскалацией западных стран в отношении к России, обусловливает жесткую приори- 
тизацию и локализацию в реализации проектов отрасли овощеводства защищенного грунта. В связи с тем, что отрасль овощеводства защищенного грунта функционирует в условиях жесткой ограниченности финансовых ресурсов, несмотря на устойчивый рост за последние пару лет, одной из ключевых проблем остается строительство новых тепличных комплексов. Важным фактором сдерживания роста отрасли является значительная доля импортного оборудования и комплектующих в российских проектах. Хотя уровень рыночной импортоемкости снижается, однако ресурсная импортоемкость остается высокой. Кроме того, немало инвесторов пользуются услугами иностранных компаний-консультантов, специалистов в проектировании и агрономической поддержке, что в условиях падения курса рубля значительно повышает издержки. В 2016 г. в Россию было ввезено 2,9 тыс. т алюминиевых тепличных конструкций, при этом потребность в них составляла 4,5 тыс. т.

Импортозамещение - важнейший фактор снижения затрат в тепличной отрасли. Цена импортных компонентов порой в два раза выше отечественных аналогов. В связи с этим возникает объективная необходимость модернизации производства на предприятиях овощеводства защищенного грунта на основе использования отечественных технологий, российских тепличных конструкций и оборудования при строительстве тепличных хозяйств. Что безусловно положительно повлияет на эффективность проектов за счет исключения таможенных платежей, снижения транспортных расходов и с учетом низких цен на энергоносители и более дешевых трудовых ресурсов может сократить стоимость тепличного комплекса более чем на 30 \%. Немаловажно, что Россия - один из крупнейших производителей алюминия, основного материала для тепличных конструкций. В современных тепличных комплексах для выполнения каркаса кровли и остекления стен чаще всего применяется алюминиевый профиль в силу его физических свойств - малого веса и высокой коррозийной стойкости. Из него же изготавливаются столы для рассады и корпуса светильников ассимиляционного освещения. Из алюминиевого проката сваривают воздуховоды и дымовые трубы. Дополнительный эффект может дать и господдержка проектов с применением отечественных компонентов: в будущем приоритетную поддержку могут получить предприятия с долей локализации более 70 \%. Уже сейчас крупные агрохолдинги, планирующие строительство собственных тепличных комплексов, ориентируются на применение российских комплектующих. Развивая сотрудничество с иностранными партнерами в сфере проектирования тепличных комплексов и наращивая производство современных тепличных конструкций и оборудования, российские производители в ближайшем будущем имеют возможность насытить внутренний рынок, а в дальнейшем даже выйти на рынок стран СНГ и Европы.
Определенные проблемы существуют и в эффективности господдержки. В настоящее время предусмотрено около тридцати форм государственной поддержки, в том числе и для малых форм хозяйствования. Для отрасли растениеводства: несвязная поддержка (субсидии на компенсацию части затрат на 1 га площади, варьируется в зависимости от региона), субсидии на приобретение элитных семян, осуществление мелиоративных работ, приобретение сельскохозяйственной техники. В отношении последней важной особенностью является следующее: согласно действующему законодательству субсидию (25 \% от стоимости) получает производитель российской техники, а не покупатель. Подразумевается, что и для него стоимость снижена автоматически [7]. В 2016 г. Минсельхозу было выделено 1,77 млрд руб. для субсидирования в части прямых понесенных затрат создания и модернизации объектов картофеле- и овощехранилищ, 3 млрд руб. - на компенсацию объектам тепличных комплексов, 2 млрд руб. - для необходимых рынку оптовораспределительных центров, еще 2 млрд руб. - на животноводческие и растениеводческие селекционные центры [4]. Аграрии признают, что объемы поддержки растут, однако не все могут их получить. Например, остра проблема нехватки средств в муниципальном бюджете, без которых не будут распределены федеральные средства. По правилам региональные власти должны софинансировать не менее 5 \% от размера субсидии за счет средств федерального бюджета, но если в бюджете региона нет для этого достаточных сумм, то и федеральное финансирование становится невозможным. Для дальнейшего развития отечественного сельского хозяйства необходимо по возможности не только увеличить объем несвязанной поддержки, но и упростить процедуру ее получения. В настоящее время в отдельных субъектах она привязана либо к производству текущего года, либо к конкретным сельскохозяйственным культурам. Получается, что погектарные субсидии автоматически относятся к мерам «желтой корзины». Для увеличения объемов субсидирования стоит исключить данную привязку, чтобы поддержка сельскохозяйственных товаропроизводителей относилась к «зеленой корзине» [7].

В последние годы немаловажной проблемой для аграриев стала девальвация рубля. Почти все технологии и оборудование для теплиц, а также значительная часть семенного материала импортируются из-за рубежа, поэтому валютная составляющая в этом бизнесе очень высока, а цены на конечную продукцию не растут настолько, чтобы покрыть возросшие издержки на производство. К этому также следует добавить растущие цены на энергоресурсы, в связи с чем основная масса тепличных проектов реализуется в Центральном, Южном и Северо-Кавказском федеральных округах, где больше солнечных дней, чем в других регионах страны. Проблемой управления пред- 
приятиями овощеводства защищенного грунта является то, что тепличное производство относится к числу наиболее энергоемких производств. Эффективная работа тепличных комплексов не возможна без применения современных энергосберегающих технологий. При этом вопрос условий поставки энергоресурсов остается одним из самых актуальных в тепличном овощеводстве. В соответствии с действующим законодательством Российской Федерации предприятия тепличного овощеводства льготы по оплате за электрическую энергию не имеют. С целью снижения значительной доли затрат на электроэнергию в себестоимости круглогодичного производства овощной продукции (до 35 \% при стоимости электроэнергии в среднем от 4 до 5 руб./кВт·ч), рассматривается предложение по установлению для сельхозтоваропроизводителей в защищенном грунте льготного тарифа, не превышающего 50 \% от действующего.

Важнейшей проблемой можно считать монополизацию оптовой и розничной торговли крупными сетевыми компаниями и разного рода посредниками, неразвитость логистики, что существенно повышает долю неоправданно высоких трансакционных издержек в розничной торговле. Со стороны местных и федеральных властей в недостаточной степени контролируются цены на тепличную продукцию, на рынке господствуют посредники. Например, стоимость 1 кг огурца в первой половине 2017 г. составляла 170-185 руб., а тепличные организации были вынуждены продавать продукцию ниже 70-85 руб. за 1 кг, в связи с тем, что торговцы-монополисты диктуют свои цены и производителям и покупателям. Таким образом, отмечается диспропорция между ценами производителей и потребительскими ценами на тепличную продукцию. Кроме того, сильное давление торговых сетей заставляет производителей снижать цены, что сокращает доходы тепличного производства и ухудшает финансовое положение организаций.

Заключение. Для российского агропромышленного комплекса импортозамещение является стратегической задачей уже не один год наряду с модернизацией материально-технической базы, формированием инфраструктуры и развитием малого бизнеса. В условиях санкций вопрос развития отечественного производства стоит очень остро. Обязательным условием замещения импортного продовольствия российским является конкурентоспособность последнего. В декабре 2013 г. началось падение курса рубля, которое привело к снижению импортных поставок и их удорожанию. Данное обстоятельство стало отправной точкой в обсуждении Правительства РФ вопроса об импортозамещении как стратегии развития страны. Окончательно об ускорении замещения импорта на отечественную продукцию Правительство РФ объявило в марте 2014 г. [1].

В ходе исследования был проведен анализ современного состояния отрасли овощеводства защищенного грунта и выявлены актуальные проблемы и особенности:

функционирование отрасли в условиях жесткой ограниченности инвестиций;

приоритизация и локализация управления производством овощей защищенного грунта;

функционирование предприятий отрасли в условиях ограниченной и более низкой конкуренции из-за эмбарго;

трансформация системы государственной поддержки в условиях глобальных вызовов и ограничений;

необходимость на определенном этапе перехода от импортозамещающего роста на экспортно-ориентированный.

В ходе исследования были выделены положительные тенденции и результаты процесса импортозамещения в России.

Ранее доля импортных овощей и фруктов в России доходила до 70 \%. При этом большую долю российского рынка занимала Турция: по овощам - 16 \%, по фруктам - 31 \%. После запрета турецких продуктов импорт сократился, что дало возможность отечественным производителям нарастить собственное производство. Часть импорта была перераспределена между другими странами-импортерами, в частности, между Марокко, Ираном, Египтом и Китаем. После того, как был запрещен импорт овощей из Турции, производство томатов в стране выросло на $35 \%$. В прошлом году был собран рекордный урожай томатов - свыше 290 тыс. т. Пропорция своего производства и импорта сильно изменилась. Если в 2012 г. собственное производство томатов составляло 17 \%, то в 2016 г. - примерно $40 \%$. Еще лучше ситуация обстоит с огурцами. Собственное производство огурцов, по оценке Национального плодоовощного союза, в прошлом году составило почти 80 \%. Таким образом, доля тепличных овощей импортного происхождения сократилась по итогам прошедшего года до 40 \%.

\section{СПИСОК ЛИТЕРАТУРЫ}

1. Захарова Е.В. Важность инновационного импортозамещения в условиях международных санкций против российской экономики // Экономика и Право. - 2014. - №12. - Режим доступа: http://www. vipstd.ru/nauteh/index.php/---ep14-12/1346.

2. Миллиарды в закрытом грунте. - 2017. - Режим доступа: http://www.agroinvestor.ru.

3. Официальная статистика / Федеральная служба государственной статистики. - Режим доступа: http:// www.gks.ru.

4. Официальный портал Министерства сельского хозяйства Российской Федерации. - Режим доступа: http://www.mcx.ru.

5. Сергей Королёв. Возродить овощеводство, 2015. Режимдоступа:http://agbz.ru/interviews/sergey-korolev_vozrodit-ovoschevodstvo.

6. Солошенко В.М., Курасова И.И. Эффективность овощеводства закрытого грунта // Вестник курской государственной сельскохозяйственной академии .- 
2011. - № 2. - C. 36-37.

7. Суханова И.Ф., Лявина М.Ю. Совершенствование системы господдержки животноводства как инструмента политики импортозамещения // Аграрный научный журнал. - 2017. - № 12. - С. 92-95.

8. Чазова И.Ю. Организационно-экономический механизм устойчивого развития рынка овощей защищенного грунта: автореф. дис. ... канд. экон. наук. - Ижевск, 2017. - 24 с.

Бреднев Владислав Дмитриевич, аспирант ка- федры «Маркетинга и ВЭД», Саратовский государственный аграрный университет имени Н.И. Вавилова. Россия.

410012, г. Саратов, Театральная пл., 1.

Тел.: (8452) 26-27-83.

Ключевые слова: тенденции развития; производство; реализация; импортозамещение; овощи защищенного грунта.

\title{
CURRENT STATUS AND TRENDS OF DEVELOPMENT OF GREENHOUSE VEGETABLE'S PRODUCTION AND SALE UNDER CONDITIONS OF IMPORT SUBSTITUTION
}

Brednev Vladislav Dmitrievich. Post-graduate Student of the chair "Marketing and Foreign Economic Activity", Saratov State Agrarian University named after N.I. Vavilov. Russia.

Keywords: current status; trends of development; production; sale; import substitution; greenhouse vegetables.

The current status of development of greenhouse veg- etable farming sector is analyzed, central issues of business management in ground protected vegetable farming sector in modern conditions of import substitution are revealed, current special aspects of the development of greenhouse facility vegetable's production and sales are represented, prospects for the development of greenhouse vegetable farming sector enterprises are regarded.

УДК 630*644.7:631.145(045)

\section{ВЛИЯНИЕ КОЛЕБАНИЙ ЦЕН НА РАЗВИТИЕ АГРОБИЗНЕСА}

\author{
БУТЫРИН Василий Владимирович, Саратовский государственный аграрный университет \\ имени Н.И. Вавилова
}

\begin{abstract}
БУТЫРИНА Юлия Александровна, Саратовский государственный аграрный университет
\end{abstract} имени Н.И. Вавилова

МОРЕНОВА Елена Александровна, Саратовский государственный аграрный университет имени Н.И. Вавилова

ЧЕРНЕНКО Елена Владимировна, Саратовский государственный аграрный университет имени Н.И. Вавилова

Рассматривается влияние различных факторов на эффективность сельскохозяйственного производства на примере растениеводства. На основе расчетов доказывается, что наиболее сильное влияние на эффективность и развитие агробизнеса оказывает колебание иен на рынках сельскохозяйственной продукции.

Введение. На эффективность агробизнеса оказывают влияние различные факторов, которые по различным признакам можно классифицировать на разные группы : внешние и внутренние, природно-климатические и социально-экономические, организационные и технологические и т.п. Однако, не смотря на множество влияющих факторов и сложность характера их влияния, в конечном итоге, весь комплекс влияющих воздействий аккумулируется и определяет эффективность агробизнеса через несколько ключевых показателей, с помощью которых и рассчитываются конечные финансовоэкономические результаты деятельности агропредприятий: прибыль, доходность, уровень рентабельности производства и продаж. Рассмотреть данную систему влияния целесообразно на примере растениеводства, являющегося наиболее рискованной отраслью, подверженной воздействию как производственных, так и коммерческих рисков.
На эффективность данной отрасли, как и других отраслей, влияют рынок продукции и рынок ресурсов. Рынок ресурсов, оказывая опосредованное влияние через технологический процесс в конечном итоге приводит к формированию одного из ключевых результативных показателей - удельные затраты на 1 га посева той или иной культуры. Удельные затраты, аккумулируя влияние комплекса факторов при воздействии погодно-климатических условий формируют показатель урожайности культур и на основе ее величины определяют уровень себестоимости производимой продукции.

Урожайность - ключевой показатель эффективности в растениеводстве, величина которого на фоне низкого уровня применяемых технологий в большой степени зависит от погодно-климатических условий. Внедрение современных технологий возделывания культур позволяет снизить эту зависимость и существенно увеличить уровень 